\title{
Accumulation of Hedgehog-Responsive Progenitors Parallels Alcoholic Liver Disease Severity in Mice and Humans
}

\author{
Youngmi Jung ${ }^{\star}$, Kevin D. Brown", Rafal P. Witek ${ }^{*}$, Alessia Omenetti ${ }^{*}$, Liu Yang ${ }^{\star}$, Margon \\ Vandongen ${ }^{\star}$, Richard J. Milton ${ }^{\ddagger}$, lan N. Hines ${ }^{\ddagger}$, Richard A. Rippe ${ }^{\ddagger}$, Laurent Spahr ${ }^{\S}$, Laura \\ Rubbia-Brandt $\|$, and Anna Mae Diehl ${ }^{\star}$
}

*Department of Medicine, Duke University, Durham, North Carolina ‡Department of Medicine, University of North Carolina, Chapel Hill, North Carolina §Department of Gastroenterology and Hepatology "Department of Pathology, University Hospital, Geneva, Switzerland

\begin{abstract}
Background \& Aims-Improving outcomes in alcoholic liver disease (ALD) necessitates better understanding of how habitual ethanol $(\mathrm{EtOH})$ consumption alters normal regenerative mechanisms within the liver. Hedgehog (Hh) pathway activation promotes expansion of progenitor populations in other tissues. We evaluated the hypothesis that chronic $\mathrm{EtOH}$ exposure activates Hh signaling in liver.
\end{abstract}

\begin{abstract}
Methods-Hh signaling, liver progenitors, transforming growth factor (TGF)- $\beta$ induction, and liver damage were compared in mice fed chow, high-fat diets (HF), or HF + EtOH for 4 weeks. Susceptibility to TGF- $\beta$-mediated apoptosis was compared in Hh-responsive liver cells (eg, immature cholangiocytes and oval cells) and mature hepatocytes (which are unresponsive to $\mathrm{Hh}$ ). Hepatic accumulation of Hh-responsive cells were compared in controls and ALD patients and correlated with a discriminant function (DF) that predicts subacute mortality.
\end{abstract}

\begin{abstract}
Results-Hh signaling and numbers of Hh-responsive cells were increased in HF mice and greatest in $\mathrm{HF}+\mathrm{EtOH}$ mice. In both, progenitor and stromal cell populations harbored $\mathrm{Hh}-$ responsive cells. More ductular-type progenitors and fibrosis markers were noted in $\mathrm{HF}+\mathrm{EtOH}$ mice than in HF mice. The former also expressed more TGF- $\beta-1$. TGF- $\beta-1$ treatment selectively promoted the viability of $\mathrm{Hh}$-responsive immature liver cells and caused mature hepatocytes that survived to produce Hh ligands. Hh-responsive cells were increased in ALD patients. Lobular accumulation of Hh-responsive immature ductular cells was greater in those with a DF >32 than those with a DF $<32$.
\end{abstract}

Conclusions-Hh signaling is increased in ALD and may influence ALD outcomes by promoting hepatic accumulation of immature ductular cells.

Habitual alcohol consumption promotes hepatocyte death and inhibits the proliferation of mature hepatocytes that survive, leading to chronic liver damage. ${ }^{1,2}$ Alcoholic liver damage is generally accompanied by a ductular reaction that is characterized by periportal

\footnotetext{
(C) 2008 by the AGA Institute

Address requests for reprints to: Anna Mae Diehl, MD, Florence McAlister, Professor and Chief, Division of Gastroenterology, Duke University, Snyderman Building (GSRB-1), 595 LaSalle Street, Suite 1073, Durham, North Carolina 27710.

annamae.diehl@mc.duke.edu.

Y.J. and K.D.B contributed equally to this work as first authors.

Supplementary Data

Note: To access the supplementary material accompanying this article, visit the online version of Gastroenterology at www.gastrojournal.org, and at doi:10.1053/j.gastro.2008.02.022
} 
accumulation of atypical bile duct cells (dubbed ductular cells) and associated stromal elements, including myofibroblastic cells and fibrous matrix. As in many other types of chronic liver disease, ${ }^{3}$ in alcoholic liver disease, the intensity of this ductular reaction closely parallels the severity of liver injury. ${ }^{4}$ Ductular cells, myofibroblasts, and fibrosis often extend into the hepatic parenchyma, entrap hepatocytic cells, and bridge adjacent portal tracts as fatty liver damage progresses. ${ }^{5}$ Studies in experimental animals and humans with various types of chronic liver disease consistently demonstrate high proliferative activity in these stromal and ductular cells and show that many of them express markers of immature cells. ${ }^{6,7}$ These findings support the concept that the ductular reaction represents an expansion of the progeny of typically inconspicuous liver progenitors that reside along Canals of Hering in healthy adult livers and suggest that the ductular reaction is involved in liver repair. ${ }^{8}$ Fortunately, knowledge about the mechanisms that regulate the ductular response to liver injury is growing ${ }^{9-13}$ because such information might suggest novel therapeutic targets to reduce fibrosis and improve regeneration in individuals with alcoholinduced liver injury.

Recently, our group discovered that several of the major cell types that participate in the ductular reaction, namely bipotent hepatic progenitors (ie, oval cells), immature cholangiocytes, and liver myofibroblasts, produce and respond to Hedgehog (Hh) ligands. ${ }^{14-16}$ This insight has potential relevance for liver repair because Hh signaling orchestrates embryogenesis, as well as the remodeling of many adult tissues after injury. ${ }^{17-24} \mathrm{We}$ reported that bile duct injury is accompanied by strong induction of $\mathrm{Hh}$ signaling in portal tract stromal cells and bile ductular cells in both rodents and humans. ${ }^{16,25}$ However, it is not clear whether parenchymal liver damage, such as that induced by chronic alcohol consumption, leads to similar activation of Hh signaling. If alcoholic liver injury does induce Hh signaling, it will be important to identify the cell types, mechanisms involved, and clinical implications.

The present study evaluates the hypothesis that Hh signaling is activated in cells that participate in the ductular reaction elicited by chronic alcohol-induced liver injury. Our analysis included cultured cells, a mouse model of alcohol-induced steatohepatitis, and liver biopsy samples from patients with clinically advanced alcoholic liver disease. The results support our hypothesis and identify a previously unrecognized link between accumulation of Hh-responsive progenitors and risk for short-term mortality in patients with severe alcoholic steatohepatitis.

\section{Materials and Methods}

\section{Animal Studies}

Sixteen adult male mice (from Jackson Laboratories, Bar Harbor, ME) were divided into 3 groups. Group $1(n=4)$ was fed regular chow ad libitium, and group $2(n=4)$ and group 3 $(n=9)$ were pair fed high-fat liquid diets without (group 2) or with (group 3) ethanol $(\mathrm{EtOH})$ via continuous intragastric infusion. ${ }^{26}$ Mice were monitored closely during the 4week feeding period to assure comparable rates of weight gain in the pair-fed groups. At the end of the study, all animals were killed to obtain serum and liver tissue for analysis.

\section{Laboratory Analyses}

Serum aminotransferases were measured by an autoanalyzer in a local commercial laboratory. Total RNA was extracted from freeze-clamped liver samples that had been stored at $-80^{\circ} \mathrm{C}$. After assuring RNA quality and concentration, gene expression was evaluated by quantitative reverse-transcription polymerase chain reaction (QRT-PCR) analysis. ${ }^{16}$ The sequences of primers for mice are summarized in the Supplemental Table 
(see Supplementary Table online at www.gastrojournal.org). Formalin-fixed, paraffinembedded liver sections were stained with H\&E to assess general histology; Sirius red staining was used to evaluate liver fibrosis, ${ }^{16}$ and immunohistochemistry was done to localize expression of Hh target genes and other cell markers. ${ }^{25}$ Primary antisera were used at the following dilutions: anti-Ptc (sc-6149, 1:50; Santa Cruz Biotechnology, Santa Cruz, CA), anti-Gli2 (ab 26056, 1:1000; Abcam Ltd), cytokeratin (CK) (Pan) (18-0132, 1:500; Invitrogen). In each case, staining specificity was established by demonstrating that elimination of the primary antisera abolished staining.

\section{Cell Culture Experiments}

Mature hepatocytes, AML-12 cells (ATCC; CRL-2254), immature cholangiocytes, 603B cells (provided by G. Gores, Mayo Clinic, Rochester, MN), ${ }^{27}$ and bipotent hepatic epithelial progenitors (ie, oval cells) EpC10 cells (provided by M. Dabeva, Albert Einstein College of Medicine, NY) ${ }^{28}$ were grown in regular media then were placed in serum-free media for 18 hours before transforming growth factor (TGF)- $\beta 1$ (R\&D Systems, Minneapolis, MN) at concentration of $2 \mathrm{ng} / \mathrm{mL}$ was added. Total RNA and protein were harvested at several different time points during culture (ranging from 0 to 48 hours). Gene and protein expression were evaluated by QRT-PCR and Western blot. Caspase 3/7 Assay (G7791, Promega) was performed according to the manufacturer's suggestion. Briefly, cells were seeded on 96-well plates at approximately $70 \%$ confluence, at which point they were serum starved for 18 hours, followed with TGF- $\beta 12-\mathrm{ng} / \mathrm{mL}$ treatment. Cells were analyzed at the predetermined time points by adding Caspase $3 / 7$ substrate and measuring fluorescence. AML-12 cells were propagated in Dulbecco's modified Eagle medium (DMEM)/F12 (Gibco; 11330-032), 10\% fetal bovine serum (FBS), $40 \mathrm{ng} / \mathrm{mL}$ dexamethasone (Sigma; D-4902), $5 \mu \mathrm{L} / \mathrm{mL}$ insulin (Sigma; I-0516), $5 \mathrm{ng} / \mathrm{mL}$ sodium selenite (Sigma; S-5261), $5 \mu \mathrm{g} /$ $\mathrm{mL}$ apo-transferrin (Sigma; T-2036), and $5 \mathrm{~mL}$ penicillin/streptomycin (Gibco; 15070-63). Immature cholangiocytes and EpC10 cells were cultured in DMEM (Sigma, D-6429), 10\% FBS, and $5 \mathrm{~mL}$ penicillin/streptomycin (100x).

\section{Human Studies}

Formalin-fixed, paraffin-embedded liver sections from subjects with biopsy-proven alcoholic steatohepatitis were obtained from the Department of Pathology tissue repository at the University Hospital, Geneva, Switzerland, in which tissue samples are linked to anonimized demographic and clinical data. Results in the subjects with alcoholic liver disease were compared with findings in liver samples that were obtained from 3 controls without chronic liver disease who had liver resections for colorectal metastases. The control liver tissues were obtained from the Duke University School of Medicine Tissue Bank Shared Resource and studied in accordance with National Institutes of Health and institutional guidelines for human subjects research. Unstained slides were evaluated by immunohistochemistry to localize expression of Hh target genes (as above), a progenitor marker, CK7 (M7018, 1:750; Dako), and 2 mesenchymal markers, vimentin (M7020, 1:500; Dako) and a-smooth muscle actin (a-SMA) (M0851, 1:1000; Dako). Polymerhorseradish peroxidase (HRP) anti-rabbit (K4003; Dako), rabbit anti-goat IgG-HRP (sc-2922, 1:500; Santa Cruz Biochemistry), or MACH3 mouse AP polymer kit (MP530, Biocare Medical) were used as secondary antibodies. All subjects had provided informed consent to participate in the tissue repository/data bank in accordance with National Institutes of Health and institutional guidelines.

\section{Cell Counting}

Sirius red staining, CK7, and patch (Ptc) immunohistochemical staining were assessed by morphometry (MetaView software; Universal Imaging Corp, Downington, PA). To quantify Sirius red staining, 10 randomly chosen $\times 20$ fields/section were evaluated for each mouse. 
To quantify Ptc staining, 8 midzonal areas were randomly selected/section at $\times 40$ for each mouse. After excluding the major bile duct in each portal tract (PT) from consideration, cells staining positively for Gli2 in $7 \mathrm{PT} /$ slide were counted at $\times 40$ magnification. PT selected for analysis contained portal vein that ranged from 120 to $180 \mu \mathrm{m}$. The average number of Gli2positive bile duct cells was obtained by dividing the total number of positive cells by the total number of portal tracts. Gli2-positive hepatocytes were quantified by counting total number of Gli(+) hepatocytes/field and dividing by the total number of hepatocytes/field.

\section{Results \\ EtOH Consumption Promotes Progression of High-Fat Diet-Induced Hepatic Steatosis to Steatohepatitis}

Chronic intragastric infusion of high-fat (HF) diets induced mild hepatic steatosis and focal inflammation (Figure $1 A$ ) but rarely elicited hepatocyte apoptosis (Figure $1 C$ and $E$ ). Coincident consumption of EtOH with HF diets exacerbated liver injury, as demonstrated by increased steatosis, liver cell injury (Figure $1 B$ ), and numbers of TUNEL-positive hepatocytes (Figure $1 D$ and $E$ ). Immunohistochemical assessment of caspase 3 cleavage products confirmed that EtOH treatment significantly increased hepatocyte apoptosis. The percentage of hepatocytes staining positively for activated caspase 3 was $3.6 \pm 1.9$ in chowfed controls, $0.5 \pm 0.4$ in HF-fed mice, and $37.0 \pm 20.8$ in the HF+EtOH group $(P<.05$ for $\mathrm{HF}+\mathrm{EtOH}$ vs either other control group) (representative photomicrographs are shown in Supplemental Material 1; see Supplementary Material online at www.gastrojournal.org). In addition, EtOH-fed mice tended to have elevated serum aminotransferase values (alanine aminotransferase [ALT] (IU/L): HF, $21.6 \pm 10.8$ vs EtOH, $148.3 \pm 158$ ), and QRT-PCR analysis of liver RNA demonstrated higher collagen (I)a 1 gene expression (Figure $1 F$ ), although excessive collagen deposition was not evident in Sirius red-stained liver sections (data not shown).

\section{Hh Pathway Activation Occurs During Fatty Liver Damage}

Fatty liver disease was accompanied by increased hepatic expression of both Sonic hedgehog (Shh) ligand (Figure $2 A$ ) and several Hh target genes, including the Hh receptor, patched (Ptc, Figure 2B), Gli-2, an Hh-regulated transcription factor (Figure 2C), ${ }^{29}$ and Frizzled related peptide (Frp)-1, a soluble inhibitor of canonical Wnt signaling (Figure 2D). ${ }^{30}$ Interestingly, induction of Sonic hedgehog ligand and the Hh signaling components Ptc and Gli-2 was greater in EtOH-fed mice than HF controls, whereas EtOH consumption did not potentiate HF diet-associated increases in Frp-1.

\section{Hepatic Accumulation of Hh-Responsive Cells in EtOH-Fed Mice}

As predicted by the messenger RNA (mRNA) expression data (Figure 2) and an earlier study, ${ }^{16}$ only rare bile ductular or hepatocytic (HEP) cells expressed Hh-target genes (Gli-2 or Ptc) in chow-fed controls (Figure $3 E$ and $F$ ). HF diets somewhat increased hepatic accumulation of Hh-responsive cells, as evidenced by increased numbers of bile ductular and HEP cells expressing Gli2 (Figure $3 A$ and $E$ ) or Ptc (Figure $3 B$ and $F$ ). In HF mice, Hhresponsive cells were mainly localized in and around PT. EtOH consumption resulted in overall expansion of Gli2- and Ptc-expressing cells (Figure $3 C-F$ ). These Hh-responsive cells accumulated not only around PT, but HEP Gli2/Ptc(+) cells also extended into midzonal/perivenular areas of liver lobules.

\section{Expansion of Liver Progenitor Populations and Ductular Cells in Fatty Livers}

In liver and many other tissues, mature epithelial cells are not Hh responsive. However, cells with a less differentiated and more mesenchymal phenotype often exhibit Hh activity. Such 
cells typically become unresponsive to $\mathrm{Hh}$ ligands as they differentiate and acquire a more mature epithelial phenotype. ${ }^{14,31}$ Hence, evidence for increased $\mathrm{Hh}$ activity (Figure 2) and accumulation of Hh-responsive cells in the livers of $\mathrm{HF}+\mathrm{EtOH}-\mathrm{fed}$ mice (Figure 3) suggested that EtOH-induced liver damage in mice might have promoted repopulation of the liver by relatively immature liver epithelial cells.

To investigate this possibility, liver sections were stained for AE1/AE3, a marker of bile duct cells and bipotent hepatic progenitors that are capable of generating either hepatocytes or cholangiocytes. ${ }^{28}$ Livers of healthy control mice had only rare PT cells that expressed AE1/AE3 (Figure $4 A$ ). In contrast, increased numbers of periportal ductular cells expressing AE1/AE3 were noted in both HF-control (Figure $4 B$ ) and HF + EtOH (Figure $4 C$ and $D$ ) groups. This atypical ductular response appeared to extend further out from portal areas and into liver lobules in $\mathrm{HF}+\mathrm{EtOH}$ mice than HF controls. The latter finding suggested that EtOH consumption might have disturbed the differentiation of hepatic progenitors, favoring the accumulation of ductular cells, at the expense of more hepatocytic cells. This concept was supported by QRT-PCR results. Expression of the bipotent progenitor marker CK-7 was increased fairly similarly in $\mathrm{HF}$ controls and $\mathrm{HF}+\mathrm{EtOH}-\mathrm{fed}$ mice, whereas only EtOH feeding stimulated expression of HNF-6, a transcription factor that is required for biliary tract development, ${ }^{32}$ and CK-19, a marker of immature and mature cholangiocytes (Figure $4 E) .{ }^{33}$

\section{Increased TGF- $\beta$-1 Favors Accumulation of Hh-Responsive Ductular Cells in Mice With Alcohol-Damaged Livers}

Because high TGF- $\beta-1$ promotes accumulation of cells with a ductular phenotype, whereas low TGF- $\beta$-1 permits emergence of cells that express mature hepatocyte genes during liver development, ${ }^{34}$ we evaluated TGF- $\beta-1$ mRNA expression in our mice. As others reported, ${ }^{35}$ we found that intragastric infusion of EtOH increased TGF- $\beta-1$ expression significantly (Figure $5 A$ ), raising the possibility that TGF- $\beta-1$ might have contributed to the preponderance of ductular cells in the EtOH-fed group.

To evaluate this possibility more directly, we treated various liver epithelial cell lines with TGF- $\beta-1$ and examined effects on cell viability and gene expression. TGF- $\beta-1$ exerted differential effects on cell viability (Figure $5 B$ ). Apoptotic caspases were significantly activated by treating mature hepatocytes (AML- 12 cells) with TGF- $\beta$ - 1 , whereas identical doses of this cytokine failed to activate apoptosis in immature bile ductular cells (603B cells) or bipotent hepatic progenitors (oval cells, EpC10). Interestingly, both cholangiocytes and oval cells, ${ }^{15,16}$ but not mature hepatocytes, ${ }^{14,15}$ are known to be Hh responsive. In both former cell types (but not hepatocytes), Hh ligands inhibit apoptosis and promote growth. ${ }^{15,16}$ As others recently reported, ${ }^{36}$ treatment of AML-12 cells with TGF- $\beta-1$ also down-regulated epithelial markers but up-regulated expression of various mesenchymal markers in surviving cells (see Supplemental Material 2; see Supplementary Material online at www.gastrojournal.org). Interestingly, we found that hepatocytes that escaped TGF- $\beta$ killing dramatically up-regulated their production of Ihh mRNA (Figure 5C) and protein (Figure $5 D$ ). However, they did not express appreciable levels of various Hh target genes (including Gli1, Gli2, Gli3, Ptc, or frp-1) at any of the time points evaluated (data not shown). Thus, when exposed to TGF- $\beta-1$, mature hepatocytes either die or undergo epithelial-mesenchymal transition and begin to produce Hh ligands, factors that promote the viability and growth of Hh-responsive ductular and oval cell populations. These results support the concept that enhanced exposure to TGF- $\beta-1$ contributed to the accumulation of cells with a more ductular phenotype in EtOH-fed mice. 


\section{Hh-Responsive Cells Participate in the Ductular Response to Alcohol-Induced Steatohepatitis in Humans}

Because existing small animal models of alcoholic liver disease do not perfectly recapitulate all aspects of alcohol-induced liver damage in humans, we extended our analysis of the Hh pathway to formalin fixed, paraffin-embedded liver sections from several patients with clinically severe, biopsy-proven alcoholic steatohepatitis (Table 1). Compared with controls with histologically normal livers, all patients with clinically severe alcoholic steatohepatitis had striking liver fibrosis (Figure $6 A$ ) and dramatic expansion of liver cell populations that expressed Ptc (Figure 6B) and Gli-2 (Figure 6C). These Hh-responsive cells were generally entrapped within and/or localized adjacent to fibrous septae. They exhibited morphologic features of stromal cells, atypical ductular cells, or hepatocytic cells. To characterize better the phenotypes of Hh-responsive ductular-appearing cells, serial sections were evaluated for expression of a-SMA, vimentin, and CK-7. Gli-2-expressing cells were demonstrated in ductular structures that expressed the mesenchymal markers a-SMA (Figure $6 D)^{31}$ and vimentin (Figure $6 E)^{37}$ as well as the epithelial progenitor marker CK-7 (Figure $6 F$ ). These results indicate that the ductular response that accompanies severe alcohol-induced liver damage in humans includes populations of Hh-responsive immature cells that may be undergoing epithelial-mesenchymal transitions.

\section{Accumulation of Immature Ductular Cells Correlates With Predictors of Survival in Patients With Clinically Severe Alcoholic Steatohepatitis}

Liver histology is a poor predictor of 1-month mortality in patients with acute alcoholic hepatitis. ${ }^{38}$ One-month mortality correlates better with clinical features of hepatic decompensation, such as hyperbilirubinemia and coagulopathy. Indeed, the Maddrey discriminant function $(\mathrm{DF} ; \mathrm{DF}=4.6 \times(\mathrm{PT}-\mathrm{Control}(\mathrm{sec}))+$ bilirubin in $\mathrm{mg} / \mathrm{dL})$, a formula that incorporates these clinical parameters, is routinely used to identify patients with alcoholic steatohepatitis who are at greatest risk for short-term mortality. High mortality rates are predicted by Maddrey DF values that exceed 32. ${ }^{39-41}$ Given that clearance of bilirubin and synthesis of clotting factors are functions of mature hepatocytes, the livers of patients with more severe liver dysfunction and higher mortality risk might contain greater numbers of immature liver epithelial cells. To evaluate this possibility, we compared the content and distribution of Gli-2(+) cells that coexpressed CK-7 on deidentified liver sections from patients with a DF $<32$ with those from patients with a DF $>32$. Surprisingly, this simple assessment separated the patients into 2 discrete subpopulations. Midzonal and perivenular areas of the hepatic parenchyma of high mortality-risk patients (DF >32) had significantly more Gli2/CK7(+) cells (Figure $7 B$ and $7 C$ ) than comparable areas of low mortality-risk patients ( DF <32) (Figure $7 A$ and $C$ ). When linear regression analysis was performed to assess the degree of correlation between numbers of Gli2/CK7(+) cells and other clinical/laboratory parameters, significant correlations were demonstrated between accumulation of these liver progenitors and DF $(R=0.71)$, Child-Pugh score $(R=0.80)(P$ $<.05$ for each). Higher serum bilirubin values also tended to correlate with accumulation of liver progenitors $(R=0.64)(P=.09)$. These findings support the concept that the livers of patients with worse liver function harbored greater numbers of Gli2/CK $(+)$ cells.

\section{Discussion}

This study demonstrates that $\mathrm{Hh}$ signaling is activated in cells that participate in the ductular reaction that is elicited by chronic alcohol-induced liver injury in mice and humans. The new evidence for Hh pathway activation during alcoholic liver disease complements and extends evidence that Hh signaling increases during chronic cholestatic liver diseases. ${ }^{16,25}$ The cumulative data indicate that Hh pathway activation is a common feature of various types of liver injury that mobilize hepatic progenitor populations. Our results also link $\mathrm{Hh}$ 
pathway activation, progenitor accumulation, liver dysfunction, and increased short-term risk for liver disease-related mortality. These discoveries suggest new areas for both basic and translational research. For example, it will be important to elucidate the mechanisms that regulate $\mathrm{Hh}$ signaling in injured livers and to determine if (and how) this process might be manipulated to maximize liver regeneration while minimizing liver dysfunction and architectural distortion.

Progress in characterizing and controlling Hh signaling in adults with liver injury may be facilitated by recent advances in developmental biology. Hh signaling is now widely acknowledged to regulate tissue remodeling during embryogenesis. ${ }^{42,43} \mathrm{Hh}$ ligands orchestrate tissue development by functioning as morphogens. Pathway activation evokes a complex network of autocrine and paracrine signals that ultimately expand some cell populations at the expense of others, thereby controlling the composition and localization of cells within various tissues. ${ }^{17,44}$ Apparently, similar mechanisms mediate reconstruction of adult tissues after damage because Hh pathway activation has been reported to occur during injury to various adult tissues. ${ }^{45}$ The likelihood that Hh signaling normally exerts net trophic effects in injured adults, as it does in embryos, is further supported by evidence that injection of Hh ligands improves repair of infarcted myocardium and ischemic neuropathies. ${ }^{21}$ However, appropriate constraint of Hh pathway activity is essential for good outcomes because excessive $\mathrm{Hh}$ signaling leads to developmental anomalies in embryos ${ }^{46}$ and promotes the growth of many types of cancers, including hepatocellular carcinomas and cholangiocarcinomas, in adults. ${ }^{47}$ The current results suggest that, by promoting repopulation of injured livers with immature and fibroblastic cells, overactivation of the $\mathrm{Hh}$ pathway in adults also has a novel, and more immediate, negative consequence (ie, organ dysfunction).

As during fetal development, ${ }^{46}$ multiple mechanisms are likely to participate in regulation of Hh-responsive cells during adult tissue repair. Members of the TGF- $\beta$ superfamily are important modulators of $\mathrm{Hh}$ signaling during embryogenesis. ${ }^{48}$ Similarly, we showed that TGF- $\beta-1$ induces production of Hh ligands by mature hepatocytes and demonstrated that expression of Hh ligands and Hh target genes (eg, Ptc and Gli2) paralleled that of TGF- $\beta-1$ in injured livers. Given that Hh ligands promote proliferation of immature liver epithelial cells and myofibroblasts, ${ }^{14,16,25}$ it is not surprising that we noted that increased expression of various progenitor and fibrosis markers accompanied up-regulation of Hh pathway activity in diseased livers. Also, as in fetal progenitors, in adult liver progenitors Hh activity promotes survival. Here, we demonstrated that Hh-reactive immature cholangiocytes and bipotent hepatic progenitors ${ }^{16,25}$ are protected from TGF- $\beta$-1-mediated apoptosis.

Conversely, we confirmed earlier reports that TGF- $\beta-1$ promotes apoptosis of mature hepatocytes. ${ }^{49} \mathrm{We}$ also identified another novel, albeit indirect, mechanism by which TGF$\beta-1$ might inhibit the growth of the mature hepatocyte population. This involves increased expression of $\mathrm{Hh}$ target genes, including the Wnt inhibitor Frp- $1 .{ }^{30}$ Canonical Wnt signaling is required for hepatocyte proliferation. ${ }^{50}$ Therefore, Frp-1-mediated inhibition of this process is predicted to restrict proliferation of mature hepatocytes, providing a further growth advantage for the immature and fibroblastic liver cells and helping to explain why growth of the latter 2 cell populations is inversely related to that of mature hepatocytes in damaged livers. ${ }^{50}$

In summary, our findings suggest a novel model for the progression of alcoholic liver disease and other chronic liver diseases. Liver injury incites production of various growthregulatory cytokines, including TGF- $\beta-1$. Some of these injury-related cytokines, such as PDGF-BB ${ }^{51}$ and TGF- $\beta-1$, up-regulate production of Hh ligands by certain types of resident liver cells. In the presence of the growth regulatory cytokines, cell type-related differences in Hh pathway sensitivity may provide selection pressure that helps to expand populations of 
Hh-responsive, immature liver cells and myofibroblasts, while shrinking populations of more terminally differentiated, Hh nonresponsive cells, such as mature hepatocytes. As a result, the liver becomes repopulated by immature liver epithelial cells and fibroblastic cells. This ductular reaction distorts the normal hepatic architecture and causes some degree of hepatic dysfunction, increasing the risk for liver-related mortality, at least in the short-term. On the other hand, because the ductular reaction expands progenitor populations that ultimately generate "fresh" hepatocytes to replace senescent and damaged cells, ${ }^{8,52} \mathrm{Hh}$ signaling also plays a pivotal role in liver repair. Successful reconstitution of normal hepatic structure/ function will likely necessitate eventual down-regulation of Hh signaling, however, because excessive Hh pathway activity causes dysmorphogenesis. ${ }^{42,43}$ Thus, we propose that appropriate Hh pathway activation is a prerequisite for eventual recovery from alcohol-mediated chronic liver damage.

Further research will be required to evaluate the validity of these concepts and to determine the feasibility of optimizing the most beneficial aspects of the ductular reaction. Progress may be difficult because it seems that Hh pathway activation has diverse consequences, rendering the success of simplistic all-or-none approaches that globally increase or decrease Hh signaling unlikely. Nevertheless, the identification of specific signaling intermediaries, such as the fibrogenic cytokines and Hh ligands, and the cells that produce and/or respond to these factors during liver injury represents an important initial step in this process.

\section{Supplementary Material}

Refer to Web version on PubMed Central for supplementary material.

\section{Acknowledgments}

Supported in part by funds from NIAAA 5RO1-AA010154 (to A.M.D.). The authors thank Carl Stone for administrative support.

\section{Abbreviations used in this paper}

$\begin{array}{ll}\text { CK } & \text { cytokeratin } \\ \text { DF } & \text { discriminant function } \\ \text { Frp } & \text { Frizzled related peptide } \\ \text { Gli2 } & \text { Glioblastoma } \\ \text { Hh } & \text { Hedgehog } \\ \text { HF } & \text { high fat } \\ \text { HNF6 } & \text { hepatocyte nuclear factor-6 } \\ \text { Ptc } & \text { patch } \\ \text { PT } & \text { portal tract }\end{array}$

\section{References}

1. Diehl AM. Recent events in alcoholic liver disease V. Effects of ethanol on liver regeneration. AM J Physiol Gastrointest Liver Physiol. 2005; 288:G1-G6. [PubMed: 15591584]

2. Yip WW, Burt AD. Alcoholic liver disease. Semin Diagn Pathol. 2006; 23:149-160. [PubMed: 17355088]

3. Roskams T, Desmet V. Ductular reaction and its diagnostic significance. Semin Diagn Pathol. 1998; 15:259-269. [PubMed: 9845427] 
4. Roskams T, Yang SQ, Koteish A, et al. Oxidative stress and oval cell accumulation in mice and humans with alcoholic and nonalcoholic fatty liver disease. Am J Pathol. 2003; 163:1301-1311. [PubMed: 14507639]

5. Richardson MM, Jonsson JR, Powell EE, et al. Progressive fibrosis in nonalcoholic steatohepatitis: association with altered ductular reaction. Gastroenterology. 2007; 133:80-90. [PubMed: 17631134]

6. Roskams T, De Vos R, Van Eyken P, et al. Hepatic OV-6 expression in human liver disease and rat experiments: evidence for hepatic progenitor cells in man. J Hepatol. 1998; 29:455-463. [PubMed: 9764994]

7. Preisegger KH, Factor VM, Fuchsbichler A, et al. Atypical ductular proliferation and its inhibition by transforming growth factor $\beta 1$ in the 3,5-diethoxycarboyl-1,4-dihydrocollidine mouse model for chronic alcoholic liver disease. Lab Invest. 1999; 79:103-109. [PubMed: 10068199]

8. Libbrecht L, Roskams T. Hepatic progenitor cells in human liver diseases. Semin Cell Dev Biol. 2002; 13:389-396. [PubMed: 12468238]

9. Kollet O, Shivtiel S, Chen YQ, et al. HGF, SDF-1, and MMP-9 are involved in stress-induced human CD34+ stem cell recruitment to the liver. J Clin Invest. 2003; 112:160-169. [PubMed: 12865405]

10. Oben JA, Roskams T, Yang S, et al. Sympathetic nervous system inhibition increases hepatic progenitors and reduces liver injury. Hepatology. 2003; 38:664-673. [PubMed: 12939593]

11. Diaz-Flores L Jr, Madrid JF, Gutierrez R, et al. Adult stem and transit-amplifying cell location. Histol Histopathol. 2006; 21:995-1027. [PubMed: 16763950]

12. Koenig S, Probst I, Becker H, et al. Zonal hierarchy of differentiation markers and nestin expression during oval cell mediated rat liver regeneration. Histochem Cell Biol. 2006; 126:723734. [PubMed: 16835754]

13. Kuhlmann WD, Peschke P. Hepatic progenitor cells, stem cells, and AFP expression in models of liver injury. Int J Exp Pathol. 2006; 87:343-359. [PubMed: 16965562]

14. Sicklick JK, Li YX, Choi SS, et al. Role for hedgehog signaling in hepatic stellate cell activation and viability. Lab Invest. 2005; 85:1368-1380. [PubMed: 16170335]

15. Sicklick JK, Li YX, Melhem A, et al. Hedgehog signaling maintains resident hepatic progenitors throughout life. Am J Physiol Gastrointest Liver Physiol. 2006; 290:G859-G870. [PubMed: 16322088]

16. Omenetti A, Yang L, Li YX, et al. Hedgehog-mediated mesenchymal- epithelial interactions modulate hepatic response to bile duct ligation. Lab Invest. 2007; 87:499-514. [PubMed: 17334411]

17. Mehlen P, Mille F, Thibert C. Morphogens and cell survival during development. J Neurobiol. 2005; 64:357-366. [PubMed: 16041752]

18. Ferguson CM, Miclau T, Hu D, et al. Common molecular pathways in skeletal morphogenesis and repair. Ann N Y Acad Sci. 1998; 857:33-42. [PubMed: 9917830]

19. Bambakidis NC, Wang RZ, Franic L, et al. Sonic hedgehog-induced neural precursor proliferation after adult rodent spinal cord injury. J Neurosurg. 2003; 99:70-75. [PubMed: 12859063]

20. Adolphe C, Wainwright B. Pathways to improving skin regeneration. Expert Rev Mol Med. 2005; 7:1-14. [PubMed: 16179092]

21. Kusano KF, Pola R, Murayama T, et al. Sonic hedgehog myocardial gene therapy: tissue repair through transient reconstitution of embryonic signaling. Nat Med. 2005; 11:1197-1204. [PubMed: 16244652]

22. Chen J, Leong SY, Schachner M. Differential expression of cell fate determinants in neurons and glial cells of adult mouse spinal cord after compression injury. Eur J Neurosci. 2005; 22:18951906. [PubMed: 16262629]

23. Mimeault M, Batra SK. Concise review: recent advances on the significance of stem cells in tissue regeneration and cancer therapies. Stem Cells. 2006; 24:2319-2345. [PubMed: 16794264]

24. Pogach MS, Cao Y, Millien G, et al. Key developmental regulators change during hyperoxiainduced injury and recovery in adult mouse lung. J Cell Biochem. 2007; 100:1415-1429. [PubMed: 17167788] 
25. Jung Y, McCall SJ, Li YX, et al. Bile ductules and stromal cells express hedgehog ligands and/or hedgehog target genes in primary biliary cirrhosis. Hepatology. 2007; 45:1091-1096. [PubMed: 17464985]

26. Uesugi T, Froh M, Arteel GE, et al. Toll-like receptor 4 is involved in the mechanism of early alcohol-induced liver injury in mice. Hepatology. 2001; 34:101-108. [PubMed: 11431739]

27. Yahagi K, Ishii M, Kobayashi K, et al. Primary culture of cholangiocytes from normal mouse liver. In Vitro Cell Dev Biol Anim. 1998; 34:512-514. [PubMed: 9719406]

28. Yovchev MI, Grozdanov PN, Joseph B, et al. Novel hepatic progenitor cell surface markers in the adult rat liver. Hepatology. 2007; 45:139-149. [PubMed: 17187413]

29. Riobo NA, Lu K, Ai X, et al. Phosphoinositide 3-kinase and Akt are essential for Sonic Hedgehog signaling. Proc Natl Acad Sci U S A. 2006; 103:4505-4510. [PubMed: 16537363]

30. Katoh Y, Katoh M. WNT antagonist, SFRP1, is Hedgehog signaling target. Int J Mol Med. 2006; 17:171-175. [PubMed: 16328026]

31. Sicklick JK, Choi SS, Bustamante M, et al. Evidence for epithelialmesenchymal transitions in adult liver cells. Am J Physiol Gastrointest Liver Physiol. 2006; 291:G575-G583. [PubMed: 16710052]

32. Clotman F, Lannoy VJ, Reber M, et al. The onecut transcription factor HNF6 is required for normal development of the biliary tract. Development. 2002; 129:1819-1828. [PubMed: 11934848]

33. Durnez A, Verslype C, Nevens F, et al. The clinicopathological and prognostic relevance of cytokeratin 7 and 19 expression in hepatocellular carcinoma. A possible progenitor cell origin. Histopathology. 2006; 49:138-151. [PubMed: 16879391]

34. Clotman F, Jacquemin P, Plumb-Rudewiez N, et al. Control of liver cell fate decision by a gradient of TGF $\beta$ signaling modulated by Onecut transcription factors. Genes \& Development. 2005; 19:1849-1854. [PubMed: 16103213]

35. Bardag-Gorce F, French BA, Dedes J, et al. Gene expression patterns of the liver in response to alcohol: in vivo and in vitro models compared. Exp Mol Pathol. 2006; 80:241-251. [PubMed: 16770850]

36. Kaimori A, Potter J, Kaimori JY, et al. Transforming growth factor- $\beta 1$ induces an epithelial-tomesenchymal transition state in mouse hepatocytes in vitro. J Biol Chem. 2007; 282:2208922101. [PubMed: 17513865]

37. Robertson H, Kirby JA, Yip WW, et al. Biliary epithelial-mesenchymal transition in posttransplantation recurrence of primary biliary cirrhosis. Hepatology. 2007; 45:977-981. [PubMed: 17393507]

38. Diehl AM, Boitnott JK, Herlong HF, et al. Effect of parenteral amino acid supplementation in alcoholic hepatitis. Hepatology. 1985; 5:57-63. [PubMed: 3917968]

39. Haber PS, Warner R, Seth D, et al. Pathogenesis and management of alcoholic hepatitis. J Gastroenterol Hepatol. 2003; 18:1332-1344. [PubMed: 14675260]

40. Carithers RL Jr, Herlong HF, Diehl AM, et al. Methylprednisolone therapy in patients with severe alcoholic hepatitis. A randomized multicenter trial. Ann Intern Med. 1989; 110:685-690. [PubMed: 2648927]

41. Dunn W, Jamil LH, Brown LS, et al. MELD accurately predicts mortality in patients with alcoholic hepatitis. Hepatology. 2005; 41:353-358. [PubMed: 15660383]

42. Nagase T, Nagase M, Machida M, et al. Hedgehog signaling: a biophysical or biomechanical modulator in embryonic development? Ann N Y Acad Sci. 2007; 1101:412-438. [PubMed: 17332081]

43. Ingham PW, Placzek M. Orchestrating ontogenesis: variations on a theme by sonic hedgehog. Nat Rev Genet. 2006; 7:841-850. [PubMed: 17047684]

44. Matise MP. Order in the classroom: graded responses to instructive Hh signaling in the CNS. Cell Cycle. 2007; 6:1194-1199. [PubMed: 17495537]

45. Dellovade T, Romer JT, Curran T, et al. The hedgehog pathway and neurological disorders. Annu Rev Neurosci. 2006; 29:539-563. [PubMed: 16776596]

46. Li Y, Zhang H, Choi SC, et al. Sonic hedgehog signaling regulates Gli3 processing, mesenchymal proliferation, and differentiation during mouse lung organogenesis. Dev Biol. 2004; 270:214-231. [PubMed: 15136151] 
47. Sicklick JK, Li YX, Jayaraman A, et al. Dysregulation of the Hedgehog pathway in human hepatocarcinogenesis. Carcinogenesis. 2006; 27:748-757. [PubMed: 16339184]

48. Capdevila J, Belmonte JC. Extracellular modulation of the Hedgehog, Wnt and TGF- $\beta$ signalling pathways during embryonic development. Curr Opin Genet Dev. 1999; 9:427-433. [PubMed: 10449357]

49. Nguyen LN, Furuya MH, Wolfraim LA, et al. Transforming growth factor- $\beta$ differentially regulates oval cell and hepatocyte proliferation. Hepatology. 2007; 45:31-41. [PubMed: 17187411]

50. Tan X, Behari J, Cieply B, et al. Conditional deletion of $\beta$-catenin reveals its role in liver growth and regeneration. Gastroenterology. 2006; 131:1561-1572. [PubMed: 17101329]

51. Bataller R, Brenner DA. Liver fibrosis. J Clin Invest. 2005; 115:209-218. [PubMed: 15690074]

52. Roskams T. Different types of liver progenitor cells and their niches. J Hepatol. 2006; 45:1-4. [PubMed: 16723168] 

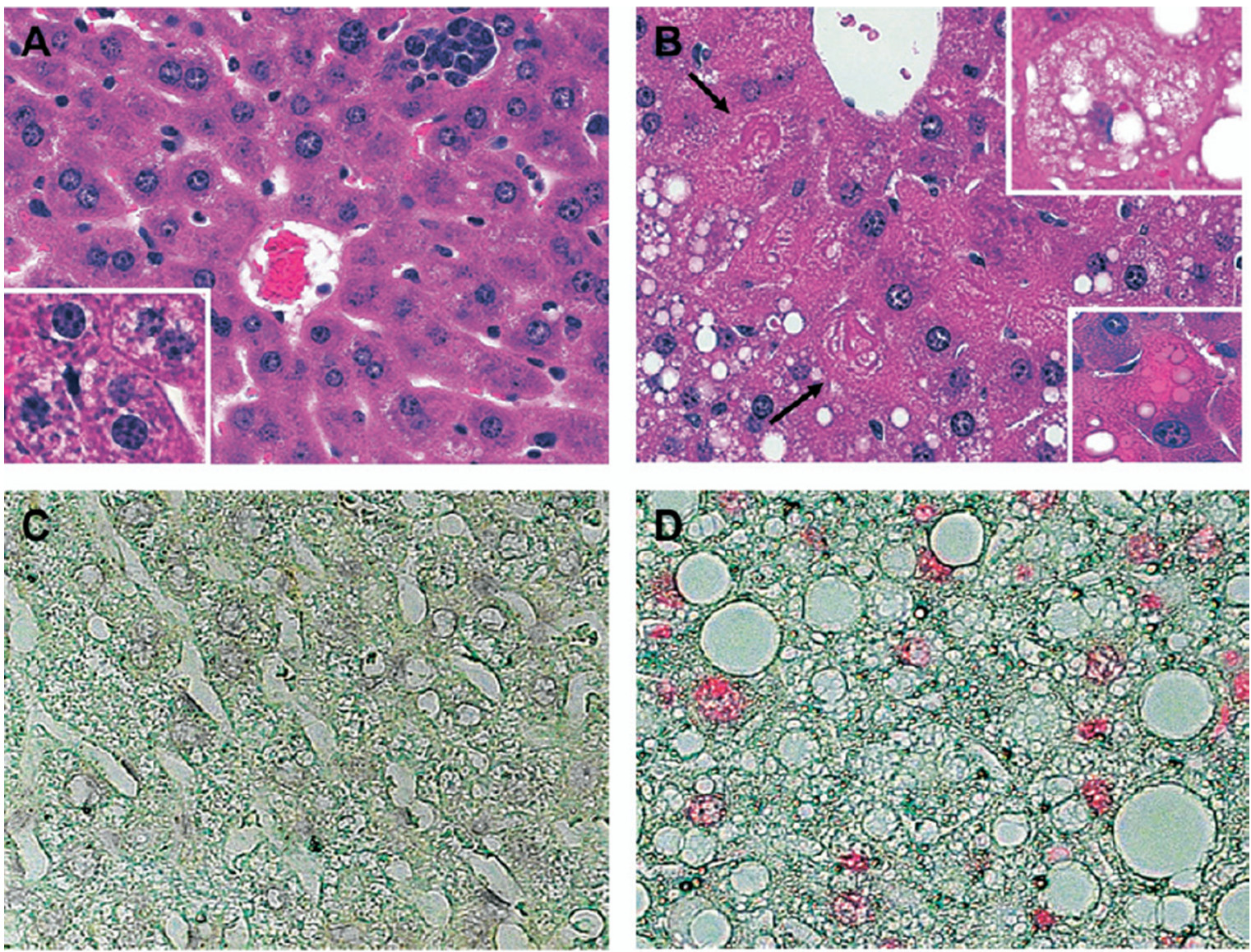

E

$\mathbf{F}$
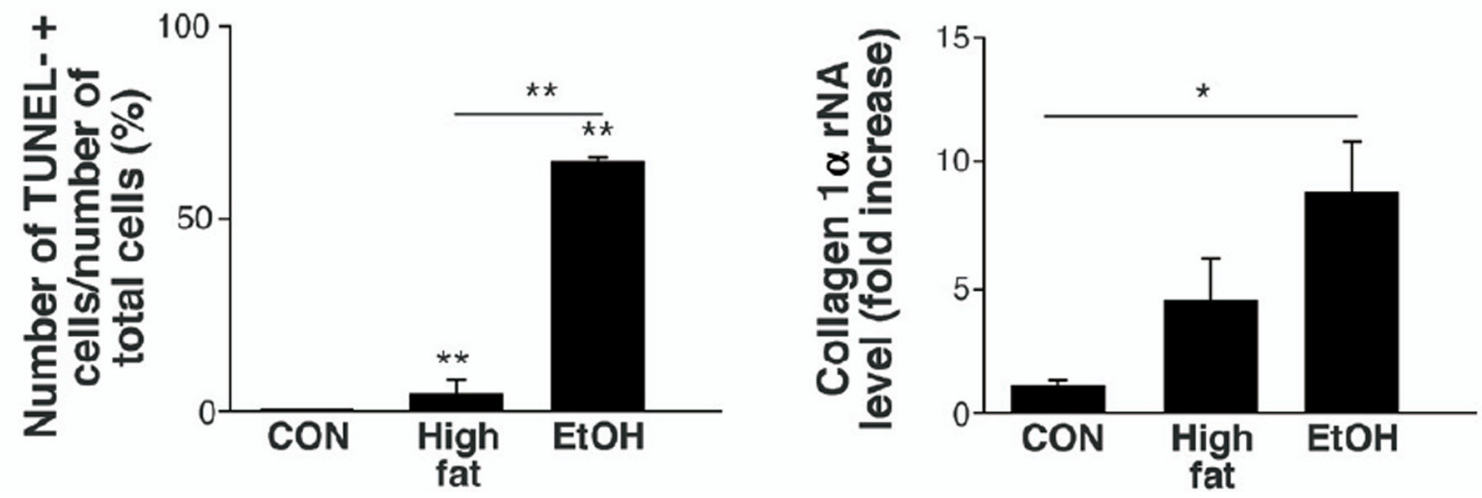

Figure 1.

Mouse model of ethanol (EtOH)-induced steatohepatitis. H\&E-stained liver sections from representative high-fat diet $(\mathrm{HF})$-fed $(A)$ and $\mathrm{HF}+\mathrm{EtOH}-f e d(B)$ mice (original magnification, $\times 40)$. Boxes inserted in $A$ and $B$, respectively, illustrate microvesicular steatosis $(A)$, steatotic ballooned hepatocyte $(B)$, and apoptotic body $(B)$ at higher magnification (original magnification, $\times 63$ ). Arrows indicate Mallory bodies. TUNELstained liver sections from representative $\mathrm{HF}(C)$ and $\mathrm{HF}+\mathrm{EtOH}(D)$ mice. Numbers of TUNEL (+) cells in chow-fed controls $(C O N, \mathrm{n}=4)$, HF mice $(\mathrm{n}=4)$, and $\mathrm{HF}+\mathrm{EtOH}$ mice $(\mathrm{n}=9)(E)$. QRT-PCR analysis of collagen $(\mathrm{I}) \mathrm{a}$ in whole liver RNA from the 3 treatment groups $(F)$. Results graphed in $E$ and $F$ are expressed as mean \pm SD. $* P<.05$; $* * P<.005$. 

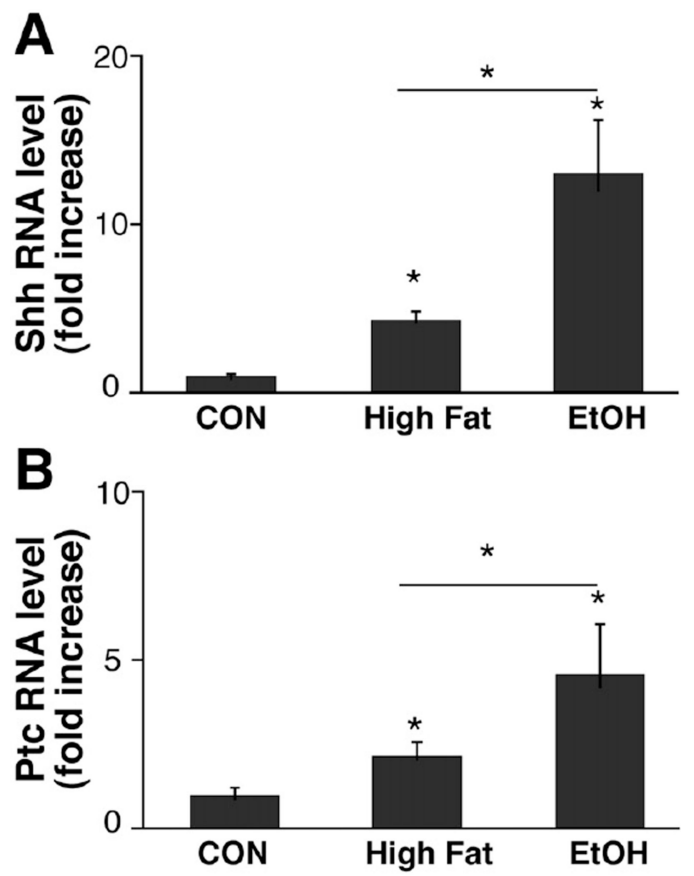

C
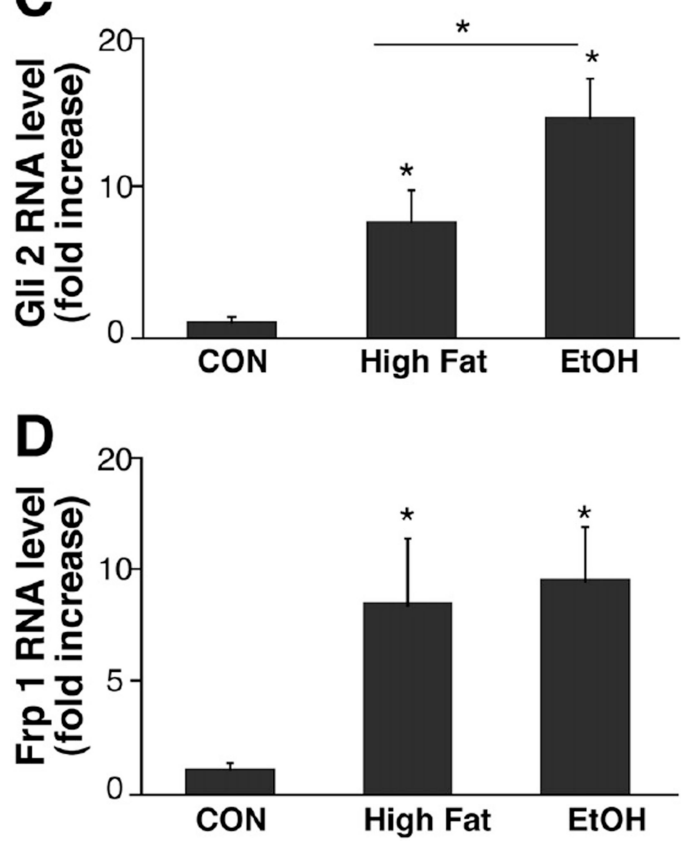

Figure 2.

Increased expression of hedgehog ligand and hedgehog target genes in fatty livers. RNA was isolated from the livers of chow-fed controls $(C O N, \mathrm{n}=4)$, HF mice $(\mathrm{n}=4)$, and $\mathrm{HF}+$ EtOH mice $(\mathrm{n}=9)$ and analyzed by QRT-PCR. Results are graphed as mean $\pm \mathrm{SD}$ for Sonic hedgehog $(S h h)(A)$, Patched $(P t c)(B)$, Gli2 $(C)$, and Frizzled related peptide $(F r p) 1(D)$. ${ }^{*} P$ $<.05 ; * * P<.005$. 

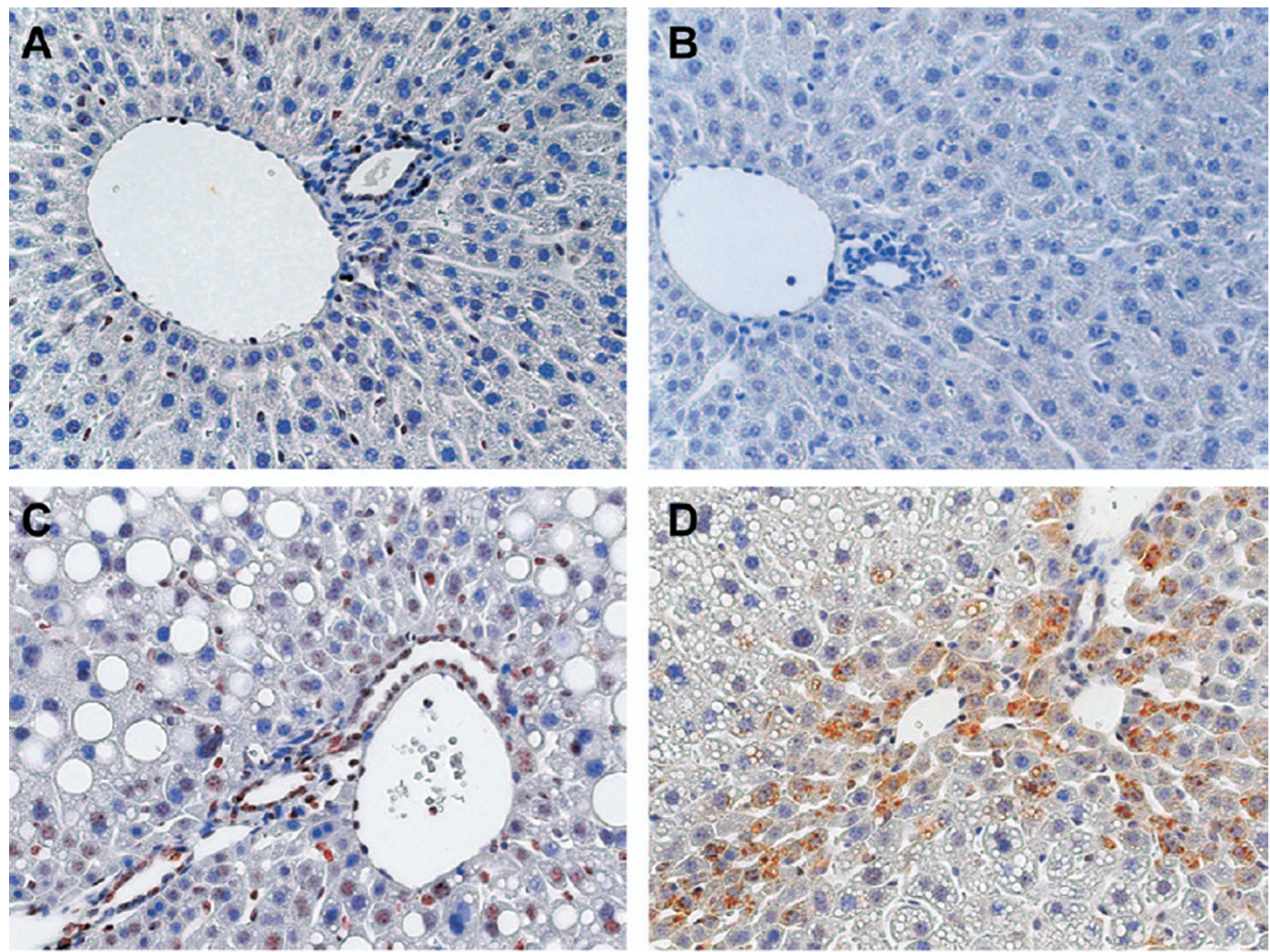

E

$\mathbf{F}$
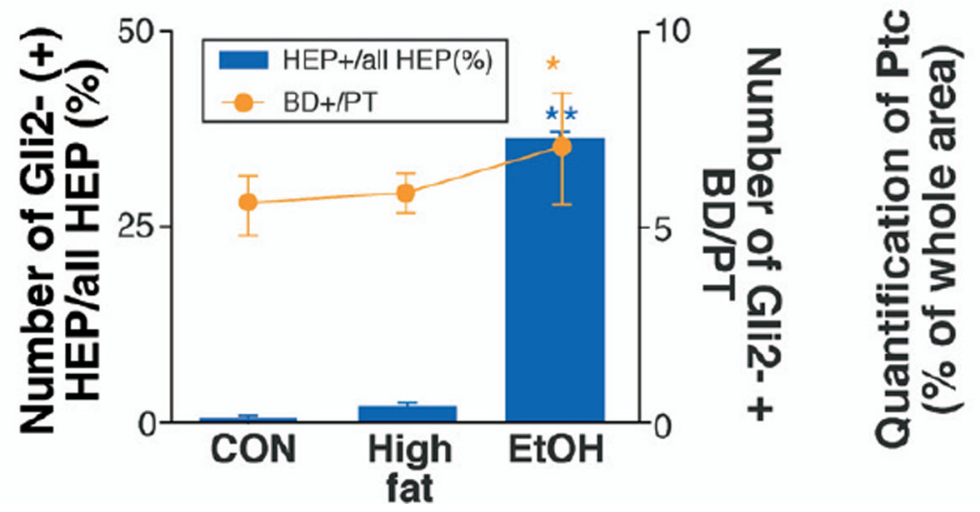

Figure 3.

Hepatic accumulation of cells expressing Hh-target genes, Gli2 and Ptc, in HF and HF + $\mathrm{EtOH}$ mice. Immunohistochemical staining was performed on liver sections from 3 randomly selected mice/treatment group. Gli2 ( $A$ and $C$ ) and Patch (Ptc) $(B$ and $D$ ) in representative $\mathrm{HF}$ mice $(A$ and $B)$ and $\mathrm{HF}+\mathrm{EtOH}$ mice $(C$ and $D)$, respectively (original magnification, $\times 40)$. Gli2(+) bile ductular cells (BD) and hepatocytic (HEP) cells were counted in 7 portal triads (PT)/section. Gli2(+) BD were expressed as number of Gli2(+) BD per PT (line graph), and Gli2(+) HEP cells were expressed as percentage of Gli2(+) nuclei/ total HEP cells (bar graph) $(E)$. Ptc $(+)$ cells were measured by morphometry in 8 midzonal 
areas/section $(F)$. Mean \pm SD results from all mice are graphed. $* P<.05, * * P<.005$ vs CON. 

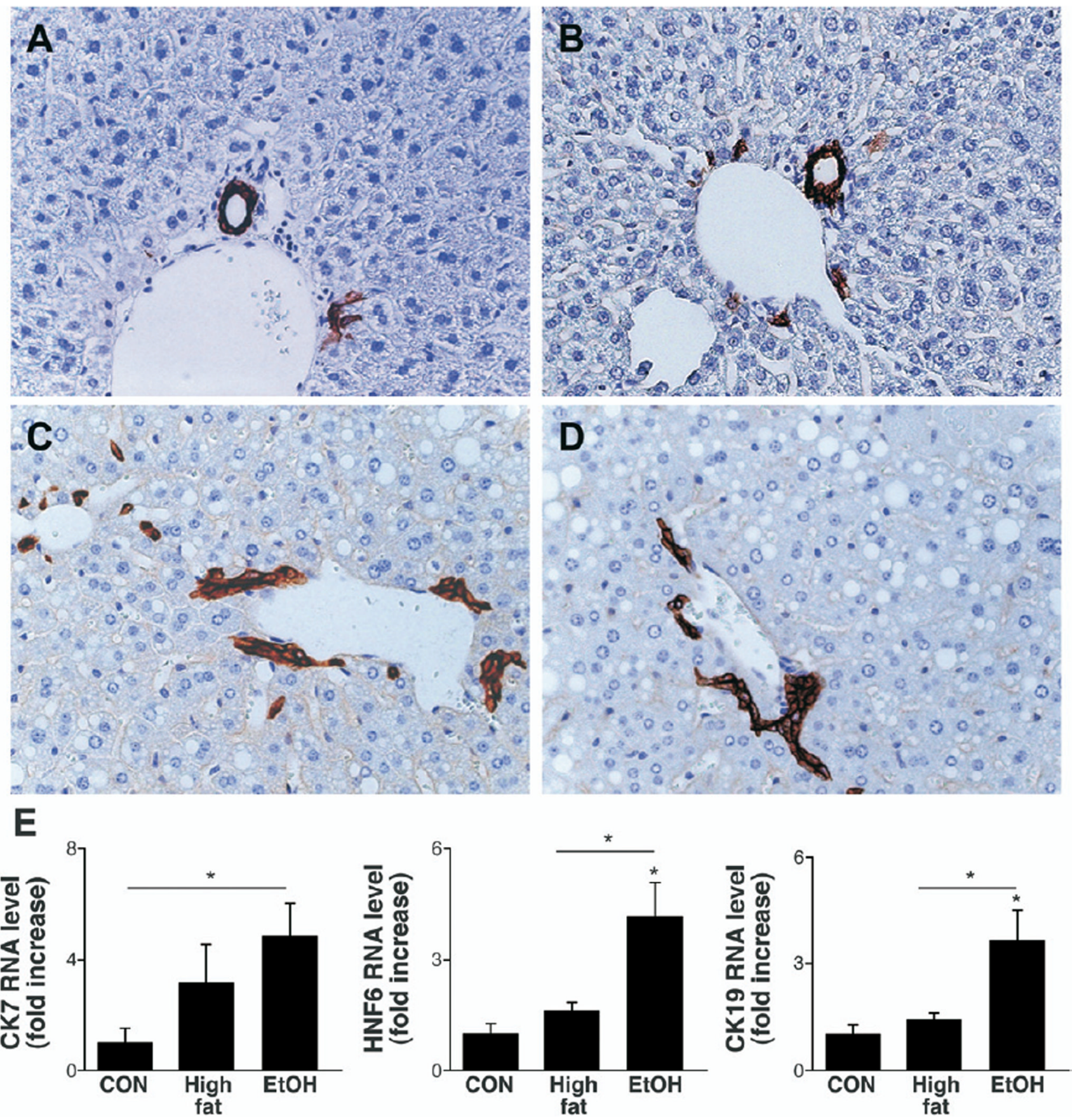

Figure 4.

Expansion of liver progenitors and bile ductular cells during fatty liver damage. AE1/3 immunohistochemical staining in a representative chow-fed control $(A)$, HF mouse $(B)$, and 2 different HF + EtOH mice $(C$ and $D$ ) (original magnification, $\times 40)$. QRT-PCR analysis of CK7, HNF6, and CK19 in whole liver RNA from chow-fed control $(C O N, \mathrm{n}=4), \mathrm{HF}(\mathrm{n}=$ $4)$, and $\mathrm{HF}+\mathrm{EtOH}$ mice $(\mathrm{n}=9)(E)$. Mean $\pm \mathrm{SD} .{ }^{*} P<.05$. 
A
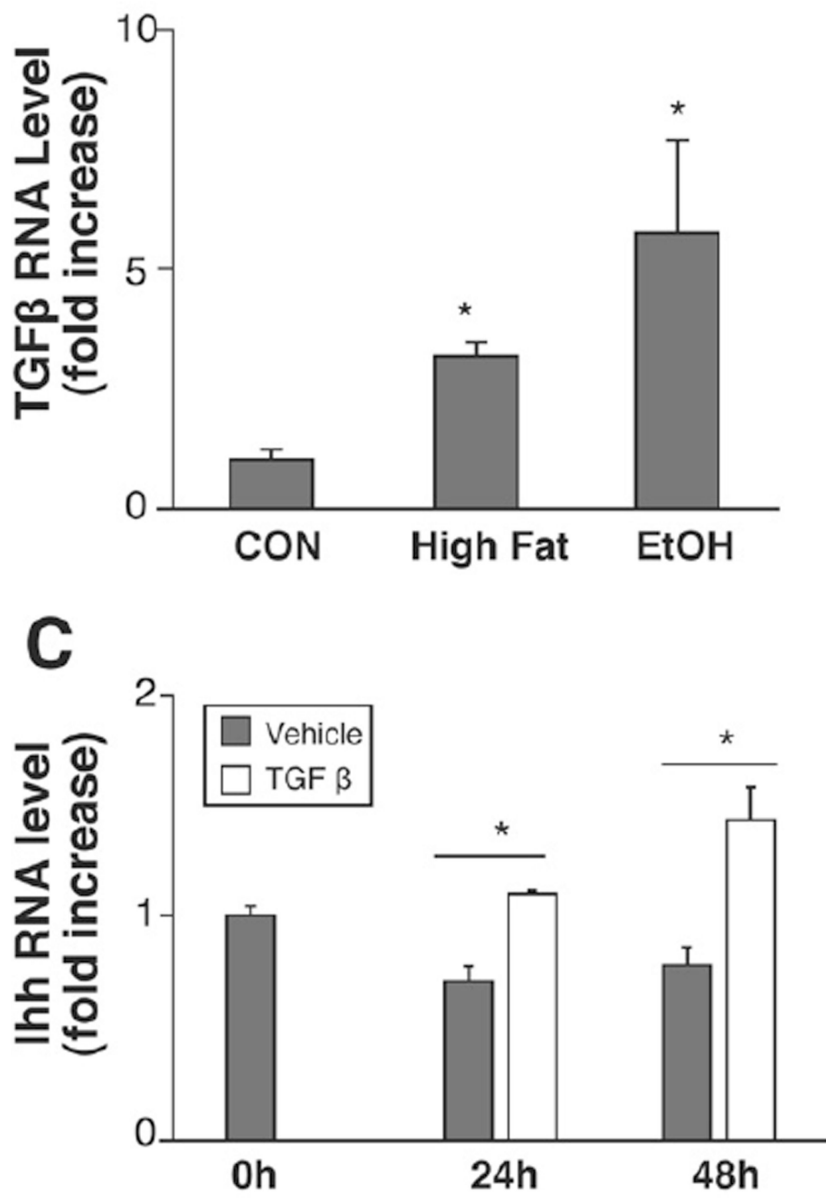

Figure 5.

Fatty liver damage induces TGF- $\beta$-1, and mature and immature liver cells respond differentially. QRT-PCR analysis of TGF- $\beta$ - 1 in whole liver RNA from chow-fed controls $(\mathrm{CON}, \mathrm{n}=4), \mathrm{HF}(\mathrm{n}=4)$, and $\mathrm{HF}+\mathrm{EtOH}(\mathrm{n}=9)$ mice $(A)$. Caspase 3/7 activity after 24hour TGF- $\beta-1$ treatment $(2 \mathrm{ng} / \mathrm{mL})$ in mature hepatocytes ( $A M L 12)$, immature cholangiocytes $(603 B)$, and oval cells $(E p C 10)(B)$. Indian hedgehog (Ihh) expression in TGF- $\beta$-treated AML12 cells. Results of QRT-PCR analysis $(C)$ and Western blot assay $(D)$. All results are displayed as mean $\pm \mathrm{SD} . * P<.05, * * P<.005$ vs $\mathrm{CON}$ or vehicle. 

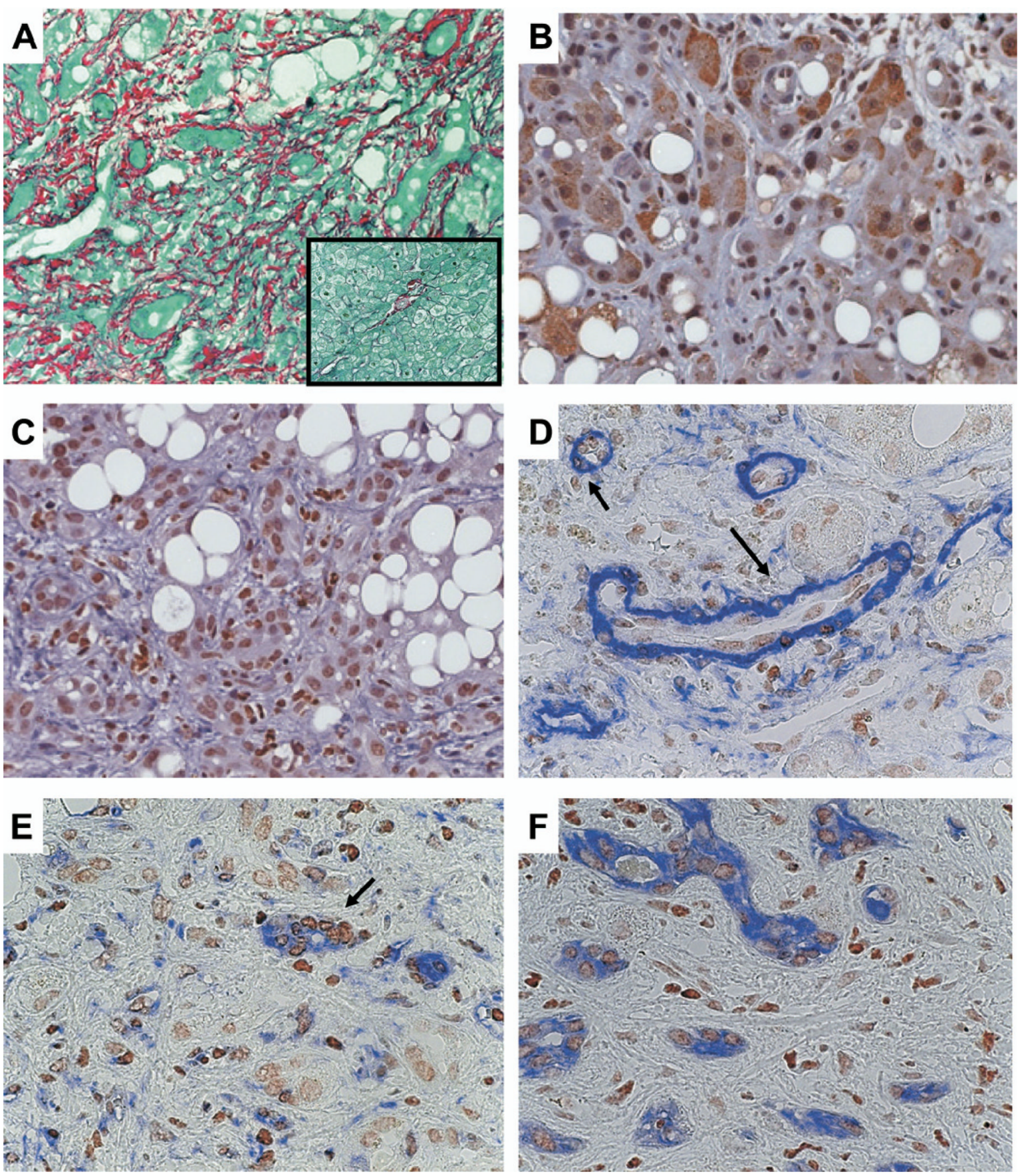

Figure 6.

Ductular response in human alcoholic liver disease (ALD). Sirius red staining in representative patient with alcoholic liver disease $(A)$. Box displays Sirius red staining from control patient with healthy liver (both $\times 40$ original magnification). Immunohistochemical staining of Ptc $(B)$ and Gli $2(C)$ in liver from representative patient with ALD (original magnification, $\times 40)$. Double immunohistochemical staining with Gli2 and aSMA $(D)$, Vimentin $(E)$, or CK $7(F)$ in representative ALD livers. Brown is Gli2, and blue is a-SMA, Vimentin, or CK 7. Arrows indicate the proliferating ductular cells, which are double positive for Gli2 and aSMA or Vimentin (original magnification, $\times 63$ ). 

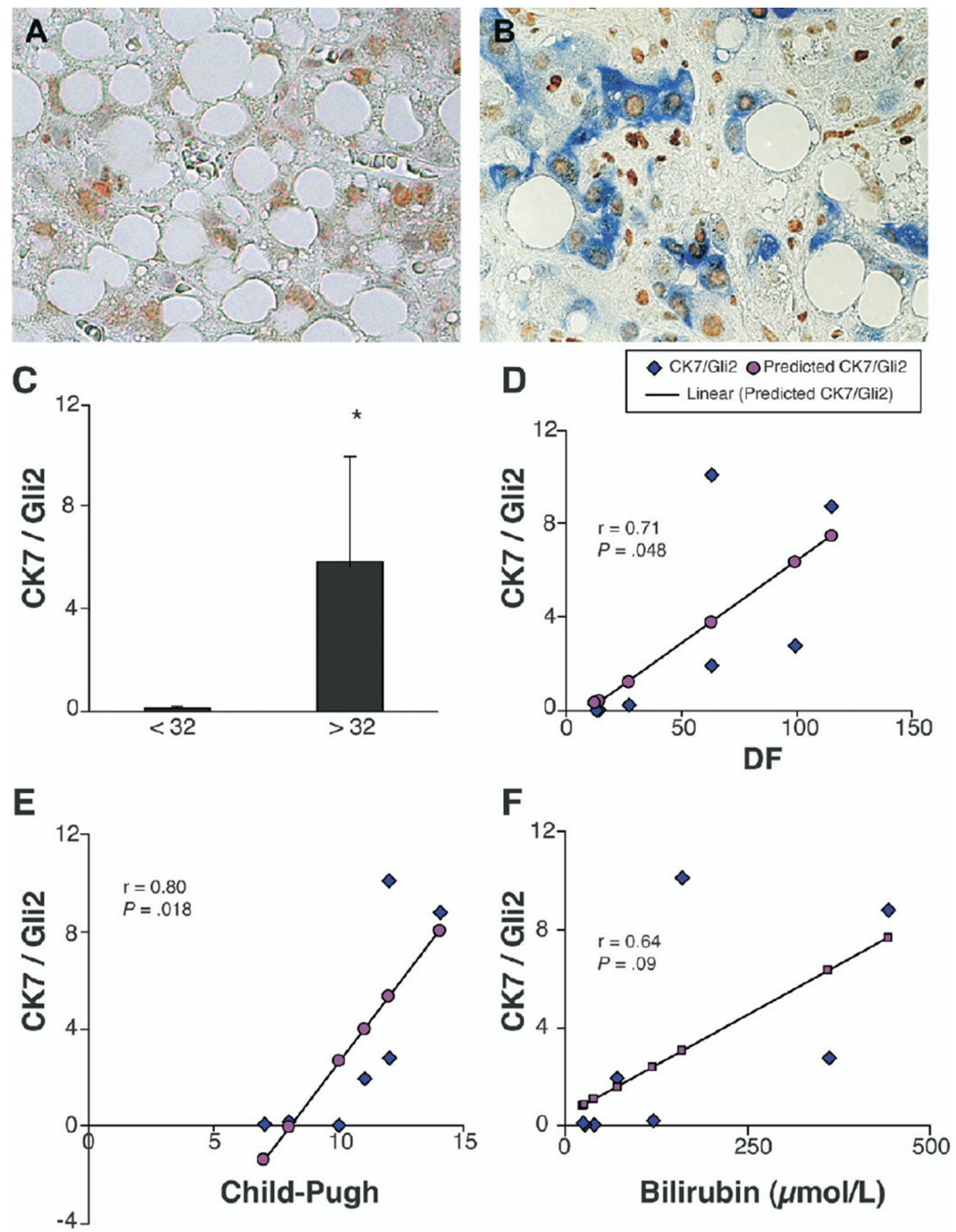

Figure 7.

Lobular accumulation of Gli2/CK7-double positive ductular cells in alcoholic steatohepatitis patients correlates with high short-term mortality risk. Double immunohistochemical staining with Gli2 (brown) and CK7 (blue) in liver parenchyma of representative patient at low risk for short-term mortality (Maddrey discriminant function $(\mathrm{DF})<32)(A)$ and another representative patient with high short-term mortality risk (Maddrey DF $>32)(B)$ (original magnification, $\times 63)$. Double $(+)$ cells were quantified by morphometry in 6 parenchymal areas/section in all subjects, and mean \pm SD results were compared in patients with Maddrey $\mathrm{DF}<32(\mathrm{n}=5)$ vs Maddrey DF $>32(\mathrm{n}=4)(C) . * P<.05$. Correlations between 
accumulation of Gli2/CK7(+) cells and DF $(D, P<.05)$, Child-Pugh score $(E, P<.05)$, and serum bilirubin $(\mathrm{F}=0.64)(P<.1)$. 
